\title{
Don Andrés Bello y su Gramática de la lengua castellana: tres hitos para la historia de la lengua común
}

\author{
Andrés Gallardo* \\ Universidad de Concepción y Academia Chilena de la Lengua, Chile
}

\begin{abstract}
Resumen
La Gramática de la lengua castellana (1847) de Andrés Bello es un texto clásico que, sin embargo, muestra una sorprendente actualidad. Se exponen tres aspectos de este libro que dan cuenta de esto: uno, la concepción cultural de la gramática; dos, la concepción de la lengua como sistema aplicada a la descripción de las clases de palabras y tres, la noción de pronombre como clase de palabra definida dentro de la estructura interna del sistema.
\end{abstract}

Palabras clave: Andrés Bello, gramática, categorías gramaticales, pronombre. Chile. 
Andrés Bello and his GRAMÁtiCA DE LA LENGUA CASTELLANA: THREE HIGHLIGHTS FOR THE HISTORY OF THE COMMON LANGUAGE

\begin{abstract}
Andrés Bello's Gramática de la lengua castellana (1840) is a classic in the Spanish grammatical tradition, which nonetheless exhibits a surprising modernity. Three aspects of this book are shown which testify to its present-day currency: one, the cultural approach to grammar, two, the notion of language as a system of signs, applied to the description of word classes, and three, the description of pronouns as a type of word within the framework of the internal structure of the language.
\end{abstract}

Key words: Andrés Bello, grammar, grammatical categories, pronoun.

Recibido: 17/03/14

Aceptado: 12/04/14

\title{
PREÁMBULO
}

La importancia de la obra de don Andrés Bello, y específicamente de su Gramática de la lengua castellana (1847), ha sido reconocida, y con plena justicia, hace ya tiempo ${ }^{1}$. No solo: la obra de don Andrés sigue concitando interés en todos los ámbitos de la cultura hispanoamericana. Con relación a la Gramática, prácticamente todos los aspectos de esta obra fundamental para el desarrollo de nuestra concepción de la lengua, tanto en su carácter de sistema de signos como en su condición de institución cultural, han sido reconocidos incluso más allá del ámbito hispánico².

En esta breve presentación, y más allá de la ponderación o del análisis erudito, dentro del espíritu interdisciplinario de la Cátedra Andrés Bello, solo se pretende poner de manifiesto la impresionante actualidad de la Gramática

\footnotetext{
1 Las biografías de don Andrés comenzaron a publicarse casi inmediatamente después de su muerte. El texto de Amunátegui (1882) sigue siendo un clásico imprescindible, así como el de Orrego Vicuña (1953).

2 Entre los trabajos panorámicos de divulgación, el estudio de Rosenblat (1961) sigue siendo un texto de consulta plenamente válido, y el de Rabanales (1982) es una excelente valoración más actualizada de las ideas lingüísticas de don Andrés.
} 
de la lengua castellana. Para ello, se mostrarán tres aspectos de esta obra fundamental, tres verdaderos hitos que parecen particularmente dignos de atención en los tiempos que corren. El primer hito tiene que ver con la integración de la gramática, en el sentido de texto que expone la estructura y el funcionamiento de la lengua, en su entorno cultural; el segundo hito se refiere a la concepción misma de la estructura gramatical de la lengua como sistema, en una perspectiva algo más teórica, y el tercer hito describe un aspecto puntual del análisis de una categoría lingüística específica, a saber, la noción de pronombre.

\section{PRIMER HITO}

En el caso de un idioma estandarizado ${ }^{3}$, es conveniente distinguir entre dos aspectos que tienen que ver con la disposición cultural de los miembros de la comunidad hablante. Un aspecto tiene que ver con el hecho de ser, simplemente, hablante de la lengua, esto es, una persona con la competencia adecuada para elaborar mensajes y para decodificarlos. Es el caso de la enorme mayoría de los hablantes, que no van más allá de su condición de tales, sin plantearse el asunto de la tradición en la cual se inserta su idioma ni el problema de su estructura y funcionamiento. El otro aspecto tiene que ver con la disposición de ciertos hablantes para, además de ser usuarios de la lengua, dar cuenta de su condición de tales, esto es, la capacidad de plantearse cómo está hecha y cómo funciona la lengua y cuál es su relevancia en el marco de la identidad cultural de la comunidad hablante.

Esta segunda situación es característica de las lenguas que han alcanzado un grado considerable de estandarización, pues presupone, por parte del hablante, la capacidad de reflexionar acerca de lo que se hace, lo que lo constituye en lo que llamamos un hablante culto.

Consideremos la historia de nuestro romance castellano: si pensamos que ya en el siglo sexto este dialecto se había distanciado del todo del viejo tronco latino, constituyéndose en una lengua diferente, pasaron al menos siete siglos antes de que sus hablantes empezaran a escribirlo en forma autónoma e institucionalizada, y dos siglos más antes de que un adelantado osara escribir una descripción de su estructura y funcionamiento. Este adelantado fue el 
maestro Antonio de Nebrija y su obra pionera, la Gramática de la lengua castellana, es de 1492. Antonio de Nebrija nos muestra, entre otras cosas, el sentido cultural de la elaboración de una gramática: constituirse en una forma de apropiación de la lengua materna como una institución reconocible, susceptible de ser usada en todas la circunstancias de la vida social, desde los menesteres más básicos hasta los productos más explícitamente normados e intelectualizados y, en consecuencia, una manifestación básica de la autonomía de la comunidad y garantía de unidad no solo comunicativa, sino cultural, política, territorial y, en el caso de Nebrija, religiosa ${ }^{4}$. Así vio el sentido de su obra el propio maestro Nebrija al referirse, en expresión tan clásica como malentendida, a "la lengua compañera del imperio", esto es, encarnación de una identidad nacional y de un proyecto compartido. (Al mismo tiempo, Nebrija entendió la relevancia de enfatizar la autonomía propiamente estructural de la lengua como sistema de signos, dejando en claro que su sistema de escritura, sus categorías gramaticales básicas y su modo de organizar una visión propia del mundo la hacían una digna sucesora y continuadora preclara de las grandes lenguas que la historia le ponía como ejemplo: el hebreo, el griego y el latín). De algún modo, la prodigiosa expansión de la lengua castellana por el ancho mundo tuvo un sustento simbólico en la obra del maestro Nebrija.

A partir del siglo dieciséis, más y más intelectuales, escritores y líderes políticos, religiosos y culturales afianzan el desarrollo de la lengua castellana como un idioma estandarizado capaz de sustentar la armazón comunicativa de un vasto imperio. Maestros gramáticos y lexicógrafos, como Gonzalo de Correas y Sebastián de Covarrubias son cumbres en este aspecto, junto con los grandes creadores que asientan un sistema de actitudes lingüísticas y culturales y un corpus literario que permiten hablar de verdaderos clásicos de una lengua que rebasa cada día más los límites de sus modestos inicios.

En el siglo dieciocho se produce un segundo momento crucial en el desarrollo del proceso de estandarización de la lengua castellana, con la instalación, en 1713, de la Real Academia Española, lo que viene a institucionalizar la conciencia de unidad en torno a una lengua conscientemente cultivada. La Real Academia centraliza todos los aspectos

\footnotetext{
4 En Gallardo (1985) se hace un estudio del sentido de la obra gramatical en cuanto a su inserción en la dinámica cultural de una comunidad hablante. El estudio se centra, específicamente, en el caso de la importancia de la obra de Nebrija en los inicios del español como lengua nacional de España, y en el caso de la obra de Bello, como toma de conciencia de la internacionalización de la lengua, concretamente, en su inserción en la dinámica de su vigencia en Hispanoamérica.
} 
que tienen que ver con el cultivo idiomático intelectualizado de modo explícito: la ortografía (publicada en 1741, haciendo cuestión central de su sustento en la pronunciación más que en otras consideraciones), el léxico (mediante un estupendo diccionario, editado en varios tomos a partir de 1726) y la gramática (cuya primera edición es de 1771). Hay dos aspectos extraordinariamente relevantes de la temprana labor académica: uno es el carácter de institución de servicio que se impuso la corporación, servicio tanto a la lengua misma, en el sentido de ser fieles a su estructura y su "lógica" interna, y servicio a la comunidad hablante, en el sentido de presentar modelos culturalmente funcionales para el cultivo intelectualizado y creativo de la lengua. Como lo demuestra aquel vetusto Diccionario de la Lengua Castellana, que hoy llamamos "diccionario de autoridades", la Academia se concibe a sí misma como entidad de autoridad delegada, pues las verdaderas autoridades son los escritores e intelectuales más caracterizados que han plasmado su huella en la lengua común. Otro punto digno de mención es el hecho de que la Real Academia se concibe, desde su fundación, como básicamente española, esto es, como institución patriótica, y concibe a la lengua como una manifestación de una tradición y de una identidad también básicamente españolas, aunque ya para entonces, de hecho, la lengua había rebasado los límites geográficos, culturales y étnicos de la mera españolidad ${ }^{5}$. Esta actitud tiene su punto culminante precisamente después de la emancipación de las naciones hispanoamericanas, cuando la Academia se erige en autoridad idiomática por sí misma (un símbolo de ello es la supresión de las citas de autores -"autoridades"- en el diccionario) y tiende a concebir la lengua española como una empresa española en un sentido más bien estrecho, marginando de algún modo la importancia de las naciones hispanoamericanas y generando una actitud de resentimiento idiomático.

En este contexto aparece, en 1847 en Santiago de Chile, la Gramática de la lengua castellana destinada al uso de los americanos, de don Andrés Bello. (Nótese, de paso, que este acto explícito de dedicar la obra "al uso de los americanos" se ha obviado en la mayor parte de las ediciones posteriores de la obra y en muchos de los estudios acerca de la misma).

Así como el maestro Nebrija planteó su gramática como una apropiación de la lengua castellana en el marco de una unidad imperial española, fuente de ejemplaridad sistematizada, don Andrés Bello plantea la suya en el

\footnotetext{
Un interesante estudio de la gramática tradicional de la Academia (concretamente, la gramática de 1931) como obra de carácter patriótico en un sentido español es el trabajo de Rabanales (1965).
} 
marco nuevo de una lengua internacional, o quizás mejor supranacional, suprageográfica y supraétnica. La mayoría de los hispanohablantes ya no es nacionalmente española, ni étnicamente de origen europeo. Así, Bello concibe la lengua común no ya como "española" en un sentido estrecho y exclusivista, sino ampliada a un rango cultural y funcionalmente muy superior. La lengua, sin dejar de ser española, es ahora la lengua de un vasto conglomerado de comunidades, una de cuyas características más relevantes es la diversidad. Para él la noción de diversidad no se contrapone con la noción de unidad, pues diversidad alude a los rasgos identitarios de naciones diversas y unidad alude a una condición interna de la lengua misma como sistema de signos, afincada en una sólida tradición. En esto, Bello difiere tanto del patriotismo idiomático estrecho de muchos intelectuales españoles como del antiespañolismo esterilizante de muchos de sus contemporáneos. Bello no reniega de la tradición, especialmente de la tradición escrita, fuente de ejemplaridad y de unidad, pues, entre otras cosas, no la considera "española" sino fuente de una continuidad comunicativa nunca rota. Para él, la literatura del pasado es un reservorio, vigente para todas las comunidades hispanohablantes, de riqueza y energía cultural, pero al mismo tiempo, entiende que la lengua ha de ser desde ahora cultivada en una dirección de participación intercomunitaria en un mundo donde los hablantes de la lengua común, que él por eso mismo prefiere llamar con el antiguo dictado de "castellana", mejor que "española", tienen el derecho a participar por igual, cada uno desde su identidad y desde su empaque cultural específico. La lengua resulta ser el instrumento de un ámbito comunicativo que se ha ampliado no solo en lo geográfico, sino que se ha enriquecido en todos los órdenes de la interacción humana y donde cada grupo y cada individuo pueden hallar su identidad y su originalidad expresiva. En otras palabras, don Andrés Bello asume pioneramente el sistema de actitudes lingüísticas propio de un idioma estandarizado. Gracias al cultivo intelectualizado de varias generaciones de creadores, pensadores y difusores, gracias a la existencia de guías como las gramáticas y diccionarios que ofrecen instituciones de estudio, los miembros de la comunidad cuentan con un marco de referencia para el comportamiento comunicativo relativamente homogéneo en su flexibilidad, pero cuentan también con un instrumento eficaz de cohesión, que al mismo tiempo que los identifica como miembros de una comunidad hablante, los conecta con el resto del mundo en una de las más amplias redes de interacción conocidas. Los hablantes de la lengua, en cuanto hablantes, ya no son españoles o mexicanos o chilenos: sin dejar de serlo, son antes que nada hispanohablantes y su identidad lingüística es, como decimos hoy, panhispánica. La Gramática de la lengua castellana de don Andrés Bello está al servicio de esta nueva visión de la lengua común. 
Por eso también, puede llamarse con justica, como lo ha hecho la Academia Chilena, "gramática de la libertad"6.

\section{SEGUNDO HITO}

Un segundo hito estructurador de la Gramática de la lengua castellana de don Andrés Bello afecta la fundamentación misma de la descripción de la estructura gramatical de la lengua, y consiste en el hecho de que para Bello la gramática debe dar cuenta simplemente de la estructura de la lengua en cuanto sistema de signos, y no de la naturaleza de los referentes de esos signos. De hecho, la gramática tradicional, desde la antigüedad, tiende a concebir la descripción de los componentes de la estructura lingüística basándose en la designación de los hechos de la vida que hacen los componentes de la lengua y en la concepción del mundo que estos implican. Así por ejemplo, se definen los sustantivos en términos de su referencia a los seres (a las "substancias"), los adjetivos en términos de su referencia a las cualidades, los verbos en términos de su referencia a las acciones de las entidades, etc. Para decirlo casi burdamente, las palabras se confunden con las cosas. De ahí que, con relación a los sustantivos, se hable, por ejemplo, de concretos y abstractos, según se puedan o no percibir por los sentidos, y de masculinos o femeninos, según se refieran a machos o a hembras, etc., sin tener en cuenta que los sustantivos, en cuanto palabras, son siempre abstractos en cuanto designan, en el mejor de los casos, clases de entidades, y que, también en cuanto palabras, no están afectos a la categoría de sexo, que es propia de algunos seres vivientes. Pues bien, Bello plantea algo realmente simple en su novedad: la gramática es una descripción de la función de las palabras y de las marcas que determinan su inserción en los enunciados, cosa que es bastante específica para cada lengua. Consecuentemente, busca definiciones que se ajusten a este principio y así, en el famoso capítulo segundo de la obra, titulado magistralmente "Clasificación de las palabras por sus varios oficios", plantea que el verbo ha de definirse por su función de constituirse en "la palabra esencial y primaria del atributo" ("sujeto"

\footnotetext{
6 Así tituló la Asociación de Academias de la Lengua Española una juiciosa antología de los principales estudios de Bello publicada con motivo del V Congreso Internacional de la Lengua Española, lamentablemente truncado en su realización física por el terremoto del 27 de setiembre de 2010 (Asociación de Academias de la Lengua Española 2010).
} 
preferimos decir hoy) y el sustantivo por su condición de ser "la palabra esencial y primaria del sujeto". Consecuentemente, una categoría básica del sustantivo, como el género, se definirá en términos de la concordancia con el adjetivo (cuando este tiene dos terminaciones), esto es, en términos morfosintácticos. Esta concepción, que la crítica ha llamado funcional, afecta hasta el día de hoy las descripciones de nuestra lengua, pero también hasta el día de hoy muchas descripciones todavía llevan la marca de la concepción "ontologista" tradicional, precisamente, entre otras cosas, en las descripciones de una categoría como el género, porfiadamente basadas en la noción de referencia al sexo.

Pero hay elementos aún más pioneramente lúcidos en la concepción funcionalista de Bello. Desde luego, sobresale su descripción del significado básico de los tiempos verbales, con la noción de significado fundamental, secundario y metafórico, en un complejo de interacciones que es todavía básicamente vigente. Y hay también otro rasgo importantísimo, no siempre reconocido. Se trata de la concepción de las clases de palabras básicas como componentes de un continuum y no como clases estancas establecidas en términos absolutamente discretos. Así, en el capítulo veinte, sobre los "derivados verbales", se expone cómo existen zonas puente entre las clases básicas, esto es, zonas de interpenetración entre ellas: así, un infinitivo "es un derivado verbal sustantivo", un participio "es un derivado verbal adjetivo" y un gerundio "un derivado verbal que hace el oficio de adverbio". Tendencias renovadoras en la concepción de la estructura gramatical y de la descripción de sus componentes básicos, como la gramática generativa, y tendencias más actuales como la orientación cognitiva, hallan en esta noción de traslapamiento una importante fuente de investigación acerca de las estructuras de estabilidad flexible de la lengua, sobre todo en su dimensión creativa.

\section{TERCER HITO}

Un tercer elemento digno de atención en la gramática de Bello, y que la crítica posterior ha tendido a subestimar, se refiere a la concepción de una categoría específica de la lengua, como es el pronombre. Desde luego, en la gramática occidental de cuño aristotélico, y concretamente en el caso hispánico desde el maestro Nebrija, se insiste en considerar el pronombre en términos del "nombre", esto es, del sustantivo, solo que como una clase especial de nombre y no como una clase funcional diferente. Se agrega más 
tarde la idea de su condición semánticamente "vacía", como si tal cosa fuera posible, matizando más modernamente la noción de "significado ocasional", como Alonso y Henríquez Ureña ${ }^{7}$ o clase "deíctica" centrada en la noción de "persona", como en la gramática académica de hoy, entendida esta última noción como alusión "a los participantes del discurso", aunque sin especificar demasiado esta noción, que está de hecho contagiada de lo que hemos llamado "ontologismo", esto es, referencia directa a los referentes del acto comunicativo: el que habla, a quien se habla, de quien se habla.

En la gramática de Bello hay, sin embargo, una observación que se suele pasar por alto, y es, precisamente, la definición propiamente funcional de la noción de pronombre:

La palabra PERSONA, que comúnmente, y aun en la gramática, suele significar lo que tiene vida y razón, lleva en el lenguaje gramatical otro significado más, denotando las tres diferencias de primera, segunda y tercera, comprendiendo en este sentido a los brutos y a los seres inanimados no menos que a las verdaderas personas (Bello 1949 [1847], $\left.\mathrm{n}^{\circ} 38\right)$.

Dejando de lado los componentes propios de su época del párrafo citado, lo sustancial es la descripción de la categoría de "persona" en términos estrictamente estructurales, como elementos de un sistema cuya identidad radica no en algún rasgo inherente a cada uno de ellos sino en la relación que establecen entre ellos en el marco de un subsistema, en este caso, precisamente la clase primaria de los pronombres personales. Más aun, Bello señala que el ámbito en el cual funciona el sistema de los pronombres es el del acto comunicativo básico, donde "primera", "segunda" y "tercera" "personas" no son propiamente los "participantes del discurso" en los términos referenciales ya señalados ("el que habla, a quien se habla, de quien se habla"), sino los elementos del acto comunicativo en cuanto tales, estos es, componentes de una estructura de lenguaje y no de un sistema de interacción social y espacialmente condicionada. En este sentido, me parece que la concepción de pronombre en Bello es extraordinariamente válida y que solamente los planteamientos de Benveniste, aún no superados, le hacen

$7 \quad$ La Gramática de la lengua castellana, de Amado Alonso y Pedro Henríquez Ureña (1949), además de ser una excelente gramática escolar, se plantea como una continuación y actualización de las ideas gramaticales del maestro Bello. Publicada unos años antes, la obra también notable de Rodolfo Lenz (1925) es otro intento de descripción de la lengua en la tradición de Bello, actualizada en este caso con los planteamientos de la lingüística decimonónica alemana. 
de algún modo eco ${ }^{8}$. Los pronombres, y específicamente los pronombres primarios, que son los personales, no son "hechos de la vida", son "realidades del discurso", hechos de lengua entendibles solo en términos de "locución" y "alocución", razón por la cual son una categoría que alcanza el rango de un universal del lenguaje humano:

Es $[\ldots]$ un hecho a la vez original y fundamental que estas formas "pronominales" no remitan a la "realidad" ni a posiciones "objetivas" en el espacio o en el tiempo, sino a la enunciación y hagan reflexivo así su propio empleo (Benveniste 1971: 175).

La noción de pronombre que entrega Bello, en apariencia tan simple, tiene todavía más consecuencias relevantes para la teoría y descripción gramatical. Es así como los pronombres significan la idea de persona, pero agregando "ya expresen esta sola idea, ya la asocien con otra", lo que significa que, además de la noción básica de las tres diferencias (o relaciones) de primera, segunda y tercera, hay otro tipo de relaciones, como las de "propiedad" (entendida no como posesión propiamente tal, sino como la asignación de una relación de dependencia de una entidad a la primera, segunda o tercera persona), tal como sucede en el caso de los pronombres llamados "posesivos", o las relaciones de espacialidad (y aun temporalidad), como en el caso de los pronombres demostrativos. La trascendencia de esto último no ha de ser desestimada, pues nos permite plantear que aquellas clases léxico-gramaticales que la tradición describe como "adverbios de lugar" son, de hecho, una subclase específica de pronombres espaciales. Con esto se pone también de manifiesto la noción tradicional de que los pronombres no constituyen una clase morfosintáctica especial, una "parte de la oración" o "clase de palabras". De hecho, pueden ser no solo sustantivos y adjetivos, sino también adverbios, pues incorporan la noción de persona delineada por Andrés Bello, esto es, categorías no absolutas sino existentes en un complejo continuum funcional. Una razón más para seguir leyendo y reflexionando acerca de la obra del maestro Andrés Bello.

8 Me refiero a los estudios de Emile Benveniste acerca del pronombre, concretamente, "La naturaleza de los pronombres", en la recopilación de sus trabajos en Benveniste (1971). 


\section{CONCLUSIÓN}

Hemos examinado, someramente, tres aspectos de la Gramática de la lengua castellana destinada al uso de los americanos de don Andrés Bello, que se constituyen en verdaderos hitos en la arquitectura de esta obra y que se proyectan hasta el día de hoy con un enorme grado de validez. Se trata de la noción de la gramática como una construcción cultural que implica una toma de posición con relación a la estructura de la lengua entendida, al mismo tiempo, como institución cultural y como sistema de signos. Así como el maestro Antonio de Nebrija representa, a fines del siglo XV, la apropiación de la lengua como un patrimonio generador de unidad española y da las bases para su cultivo culto, la obra de Bello representa un punto de inflexión en la apropiación de la lengua en una dimensión supranacional panhispánica, y señala un camino para un cultivo que amplía el ámbito cultural tradicional, pero con la garantía de una raíz común. En un sentido más teórico, la Gramática de la lengua castellana del maestro Bello representa una visión nueva de la lengua, que se describe en sí misma y por sí misma como sistema de signos, y no como una nomenclatura condicionada por el mundo de experiencias al cual alude. En este sentido, Bello se adelanta a las corrientes renovadoras de la lingüística posterior. En un aspecto más específico, Bello nos ofrece una visión del pronombre personal que permite una comprensión mucho más adecuada y profunda de esta clase de estructura de la lengua. En resumen, la Gramática de la lengua castellana, ya a más de un siglo y medio de su publicación, sigue manifestando una actualidad que no deja de asombrar.

\section{REFERENCIAS BIBLIOGRÁFICAS}

Alonso, Amado. 1951. Introducción a los estudios gramaticales de Bello. Prólogo a la Gramática (Obras completas de Andrés Bello, IV). Carcas: Ministerio de Educación.

Alonso, Amado, y Pedro Henríquez Ureña. 1949 y ss. Gramática de la lengua castellana, tomo I y tomo II. Buenos Aires: Losada.

Amunátegui, Miguel Luis. 1882. Vida de don Andrés Bello. Santiago: Pedro G. Ramírez.

Asociación de Academias de la Lengua Española. 2010. Gramática de la libertad. Andrés Bello y la unidad lingüistica panhispánica. Antología conmemorativa del V Congreso Internacional de la Lengua Española. Iván Jaksic, Fernando Lolas y Alfredo Matus (comps.). Valparaíso: Aguilar.

Bello, Andrés. 1949 [1847]. Gramática de la lengua castellana. Buenos Aires: Losada. Benveniste, Émile. 1971. Problemas de lingüística general. México: Siglo XXI. 
Gallardo, Andrés. 1978. Hacia una teoría del idioma estándar. Revista de Lingüistica Teórica y Aplicada 14: 85-119.

1985. Las gramáticas como apropiación de la lengua. Revista de Lingüística Teórica y Aplicada 23: 65-72.

1988. Un aspecto del desarrollo de la identidad lingüística chilena: José Victorino Lastarria y el Movimiento literario de 1842. Revista de Lingüística Teórica y Aplicada 26: $29-40$

Orrego Vicuña, Eugenio. 1953. Don Andrés Bello. 4. ${ }^{\text {a }}$ ed. Santiago: Zig-Zag.

Rabanales. Ambrosio. 1965. La gramática de la Academia y el estado actual de los estudios gramaticales. Boletín de Filología XVII: 261-280.

1982. Vigencia de las ideas lingüísticas y gramaticales de don Andrés Bello. En Homenaje a don Andrés Bello con motivo de la conmemoración del bicentenario de su nacimiento, pp. 81-103. Santiago: Editorial Jurídica de Chile/Editorial Andrés Bello.

Rosenblat, Ángel. 1961. El pensamiento gramatical de Bello. Caracas: Ministerio de Educación. 